\title{
Objective assessment of cortical activity changes in stroke patients before and after hand rehabilitation with and without botulinum toxin injection
}

\author{
Omnia A. Abu-Bakrª, Nagwaa M.M. Nassar, Amal M. Al-Ganzoury ${ }^{\mathrm{a}}$, \\ Khaled Abo-Elfotouh Ahmed ${ }^{\mathrm{b}}$, Eman A. Tawfik
}

${ }^{a}$ Departments of Physical Medicine,

Rheumatology and Rehabilitation,

${ }^{\mathrm{b}}$ Radiodiagnosis, Faculty of Medicine, Ain

Shams University, Cairo, Egypt

Correspondence to Omnia A. Abu-Bakr, MSc, Department of Physical Medicine,

Rheumatology and Rehabilitation, Faculty of Medicine, Ain Shams University, Abassia

Cairo, Egypt; Tel: +20 111034 4643;

e-mail: omnia_bakr@hotmail.com

Received 27 May 2016

Accepted 22 June 2017

Egyptian Rheumatology \& Rehabilitation 2017, 44:172-180

\begin{abstract}
Background
Upper limb spasticity is a disabling condition and may result in severe functional well known, but there are debates around its possible central action.

Aim outcome of two antispastic treatments for stroke of the hand and wrist. Thirty patients with upper limb poststroke spasticity were recruited in this study.

Patients and methods

They were randomly allocated to two groups: group A and group B. Both groups received rehabilitation program, whereas group $B$ received additional BTX injection. All patients were assessed at baseline and 8 weeks after treatment using the Modified Ashworth Scale, the Action Research Arm Test and Nine-Hole Peg Test, and somatosensory-evoked potential study of the median nerve.

Results wrist flexors and long flexors of fingers and in Action Research Arm Test compared with group $\mathrm{A}$.

Conclusion

BTX injection in spastic muscles of the wrist and hand, followed by a rehabilitation program led to greater clinical and functional improvement compared with implementing the rehabilitation program alone.

\section{Keywords:}

botulinum toxin, poststroke spasticity, somatosensory-evoked potentials

Egypt Rheumatol Rehabil 44:172-180

(C) 2017 Egyptian Society for Rheumatology and Rehabilitation

$1110-161 \mathrm{X}$
\end{abstract} limitation. The peripheral action of botulinum toxin (BTX) injection on spasticity is

The aim of this study was to assess the clinical, functional, and cortical activation

Group B showed a higher percentage of change in Modified Ashworth Scale of the

\section{Introduction}

Upper limb spasticity can be disabling and can result in several functional limitations. Although some neural plasticity following stroke contributes to motor recovery, maladaptive plasticity can weaken motor function and limits the recovery. Spasticity represents an example of maladaptive plasticity [1].

Local injection of botulinum toxin-A (BTX) is the standard treatment for spasticity, particularly in poststroke patients. In addition to its peripheral action, evidence of its possible effects on central nervous systems has emerged [1].

Somatosensory-evoked potential (SEP) studies in patients with spasticity showed improvement in SEP following BTX injection, which may support the possible central action of BTX in the cerebral cortex $[2,3]$.

\section{Patients and methods}

This study was conducted on 30 patients with upper limb poststroke spasticity. Patients were recruited from
Ain Shams University hospital. The study was approved by Faculty of Medicine, Ain Shams University Ethics Committee and a consent was obtained from all participant. Adult patients greater than 18 years with poststroke upper limb spasticity were included in the study. To be able to participate in the designed rehabilitation programs, they should be cooperative and achieve at least grade $\mathrm{M} 2+$ in muscle power, and score at least 1 in Modified Ashworth Scale (MAS) in their wrist and hand muscles. Patients with either hand affection were included in this study. Patients with any of the following conditions were excluded from the study:

(1) Stroke onset less than 3 months.

(2) Disease duration greater than 1 year.

(3) Peripheral nerve injuries and neuropathies.

This is an open access article distributed under the terms of the Creative Commons Attribution-NonCommercial-ShareAlike 3.0 License, which allows others to remix, tweak, and build upon the work noncommercially, as long as the author is credited and the new creations are licensed under the identical terms. 
(4) Fixed contractures of upper limbs.

(5) Association of other neurological diseases.

(6) Receptive or global aphasia.

(7) Cognitive impairment.

(8) Behavioral disturbance.

(9) Uncontrolled comorbid medical conditions.

(10) Previous BTX, alcohol, or phenol injection, or surgical intervention for spasticity.

(11) Patients with a history of previous stroke.

All patients underwent the following assessment at baseline and at 8 weeks after treatment:

(1) Clinical assessment of muscle tone of the wrist and hand muscles was carried out using the MAS [4].

(2) Functional assessment of the upper limb was carried out using the Action Research Arm Test (ARAT) [5], which is a 19-item measure divided into four subtests (grasp, grip, pinch, and gross arm movement). Performance on each item is rated on a four-point scale, in which 0 means that the patient cannot perform any part of the test and 3 means that the patient can perform the test normally. The Nine-Hole Peg Test was also used for assessment [6]; in this test patients were asked to take the pegs from a container, one by one, and place them into the holes on the board, as quickly as possible; thereafter, the patients were required to remove the pegs from the holes, one by one, and replace them back into the container. Scores were based on the time taken to complete the test activity.

(3) SEP of the median nerve was determined using the EMG/NCV Unit (EMG/NCV/EP System Topas 230/240V; Schwarzer GmbH, Germany). SEP was recorded according to the American Electroencephalography Society, 1984 international guideline for evoked potentials recording [7] using the following technique:

(a) Participant's position: The participants were examined in supine position with the arms extended and supported on the bed.

(b) Recording: Surface silver - chloride cup electrodes were used for recording.

(c) Impedance: Impedance was maintained below $5 \mathrm{k} \Omega$ and the filter bandpass was $30-3000 \mathrm{~Hz}$.

(d) Electrode position: The active electrodes were placed over the contralateral C3' or C4'. The reference electrode was situated at the $\mathrm{Fz}$ C3' and $\mathrm{C} 4$ ', and $\mathrm{Fz}$ were located using the international 10-20 system for electrode placement.

(e) Ground electrode: Ground electrode was placed over the forearm of the examined limb. (f) Stimulating electrodes: The median nerve was stimulated at the wrist. The cathode was placed between the tendons of the palmaris longus and flexor carpi radialis muscles. The anode was placed $2-3 \mathrm{~cm}$ distal to the cathode.

(g) Stimulus parameters: Stimulus parameters were as follows: Monophasic square pulses, with a pulse duration of $50 \mathrm{~m}$, stimulation frequency of $3 \mathrm{~Hz}$, and stimulus intensity sufficient to produce minimal twitches of the thenar muscles. Two traces of at least 200 averaged responses for each side were recorded.

(h) Only the cortical response was measured (N20 latency and N20-P25 peak-to-peak amplitude).

\section{Intervention}

All patients in the two groups received a full rehabilitation program for the whole hemiplegic side, three times per week for 8 weeks. The program was designed and tailored according to patient's clinical and functional assessment.

The basic components of the rehabilitation program for those patients included the following.

Superficial heat in the form of hot pack or paraffin wax was applied before stretching and strengthening exercises. Gentle passive range of motion for all joints of the hemiparetic side was performed by the therapist. Every joint was moved through the full range of movement. Exercises progressed to assisted active followed by active exercises. Different techniques of proprioceptive neuromuscular facilitation techniques were also used according to the muscle power and cooperation of each patient. Muscle strengthening exercises were also performed for all muscle groups in the involved extremities. The type of exercises were programmed according to the strength of different muscles ranging from assistive active to active against gravity and finally to resistive exercises. Biofeedback for the extensors of the wrist and fingers was obtained using Myomed 932 (Enraf, Rotterdam, Netherlands) [8]. Occupational therapy and training of self-care were carried out with consideration and incorporation of the affected side. A wrist and finger extension splint was used to prevent flexion contracture of the paretic wrist and fingers.

\section{Botulinum toxin injection}

Patients in group B received additional BTX injection. The muscles were selected according to the clinical examination of each patient; the injected muscles 
included the following: flexor carpi radialis, flexor carpi ulnaris, pronator teres, flexor digitorum profundus, flexor digitorum superficialis, and flexor pollicis longus. BTX-A $100 \mathrm{U}$ vial (Botox, Allergan Inc, Irvine, CA, USA) was reconstituted in $2 \mathrm{ml}$ of sterile nonpreserved saline. For injection, a monopolar, Teflon-coated 27-G needle electrode was used. Injection of BTX into each muscle was performed with the EMG guidance with electrical stimulation for localization of the muscle intended to be treated. BTX injections were according to the degree of spasticity, number of targeted muscles, and patient's weight. The dose for the flexor carpi radialis and ulnaris muscles was 20-100 U. For flexor digitorum profundus and superficialis muscles the dose was $20-50 \mathrm{U}$ per fascicle. For the flexor pollicis longus the dose was 10-50 U. However, for the pronator teres muscle the dose was $25-75 \mathrm{U}$. Maximum doses given were $300 \mathrm{U}$ per session. All patients in this group provided informed consent before the onset of the study.

\section{Statistical analysis}

Data were collected, revised, coded, and entered to the statistical package for the social sciences (SPSS, version 20; IBM, Armonk, New York, USA). The comparison between two groups was made using the $\chi^{2}$-test and/or the Fisher exact test and/or the Independent $t$-test. The percentage of change was defined as follows: (post-treatment-baseline)/baseline.

\section{Results}

Thirty patients with upper limb poststroke spasticity were included in this study. They were randomly allocated to two groups according to the treatment plane. Group A patients received rehabilitation program for 8 weeks. Their ages ranged from 35 to 54 years with a mean of $44.8 \pm 5.8$ years. There were 12 (80\%) male and three (20\%) female patients. Disease duration ranged from 6 to 12 months, with a mean of $9.00 \pm 2.48$ months. However, group B patients received BTX injection in addition to rehabilitation program for 8 weeks. Their ages ranged from 36 to 55 years with a mean of $46.4 \pm 5.8$ years. All patients in this group were male (100\%). Disease duration ranged from 5 to 12 months, with a mean of $9.27 \pm 2.43$ months.

There was no statistically significant difference between the two patient groups as regards age, sex, and disease duration.

At baseline, there was no significant difference between the two patient groups as regards clinical, functional, and electrophysiological data.

On comparing post-treatment data with the baseline data, group A patients demonstrated a significant reduction in MAS of long flexors of fingers and pronators, improvement in the functional scores (an increase in ARAT and decrease in the time needed to accomplish the Nine-Hole Peg Test) (Table 1 and Fig. 1), and a significant reduction in N20 latency of the SEP (Fig. 2).

However, group B demonstrated a significant reduction in MAS of wrist flexors, long flexors of fingers, and pronator, and improvement in the functional scores (increase in ARAT and decrease in the time needed to accomplish the Nine-Hole Peg Test) (Table 2 and Fig. 3), as well as a significant reduction in N20 latency and increase in N20-P25 amplitude of the SEP (Fig. 4).

On comparing the percentage of change in clinical, functional, and electrophysiological data between group A and group B, there was greater improvement in MAS of the wrist flexors and long flexors of the fingers and the ARAT in group $\mathrm{B}$ compared with group A (Table 3 and Fig. 5).

Table 1 Comparison of data at baseline and 8 weeks after treatment among group A patients

\begin{tabular}{|c|c|c|c|c|}
\hline \multirow[t]{2}{*}{ Group A patients } & \multirow[t]{2}{*}{ At baseline (mean $\pm \mathrm{SD})$} & \multirow[t]{2}{*}{ After treatment (mean $\pm S D)$} & \multirow[b]{2}{*}{ Paired $t$-test } & \multirow[b]{2}{*}{$P$} \\
\hline & & & & \\
\hline \multicolumn{5}{|l|}{ MAS } \\
\hline Wrist flexors & $2.33 \pm 0.62$ & $1.80 \pm 0.68$ & 1.948 & 0.072 \\
\hline Long flexors of fingers & $2.60 \pm 0.51$ & $1.80 \pm 0.68$ & 5.527 & $0.000^{*}$ \\
\hline Pronators & $1.93 \pm 0.70$ & $1.47 \pm 0.52$ & 3.500 & $0.004^{*}$ \\
\hline \multicolumn{5}{|l|}{ Functional scores } \\
\hline ARAT & $22.20 \pm 7.92$ & $26.40 \pm 7.79$ & -4.583 & $0.000^{*}$ \\
\hline Nine-Hole Peg Test (min) & $7.20 \pm 2.43$ & $5.27 \pm 1.80$ & 8.015 & $0.000^{*}$ \\
\hline \multicolumn{5}{|c|}{ Somatosensory-evoked potential } \\
\hline N20 latency (ms) & $25.14 \pm 3.37$ & $22.86 \pm 2.67$ & 2.747 & $0.016^{\star}$ \\
\hline N20-P25 amplitude $(\mu \mathrm{V})$ & $2.34 \pm 1.98$ & $2.55 \pm 1.72$ & -0.370 & 0.717 \\
\hline
\end{tabular}

ARAT, Action Research Arm Test; MAS, Modified Ashworth scale. $P>0.05$, nonsignificant. ${ }^{*} P<0.05$, significant. 
Although the percentage of change in N20 latency and N20-P25 amplitude was higher in group B than in group A, it did not reach a significant value (Fig. 6).

\section{Discussion}

Poststroke spasticity is associated with significant consequences for the patient's functional status and quality of life. The incidence of poststroke spasticity is variable ranging from 17 to $43 \%$ [9].

Figure 1

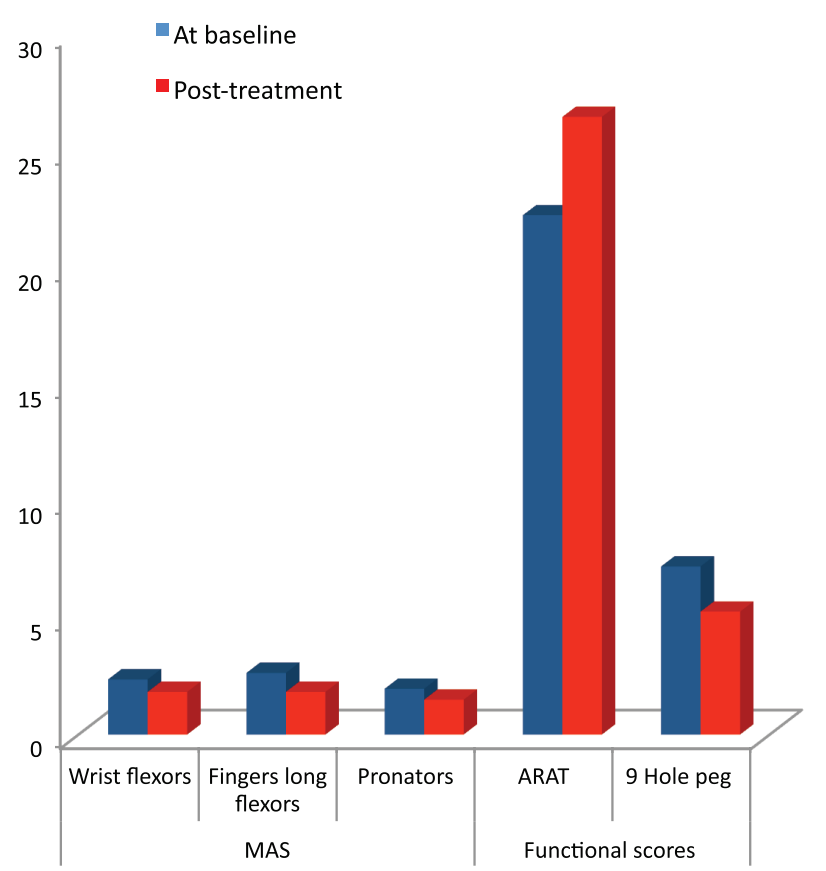

Comparison of Modified Ashworth Scale and functional data at baseline and 8 weeks after treatment among group A patients

Figure 2

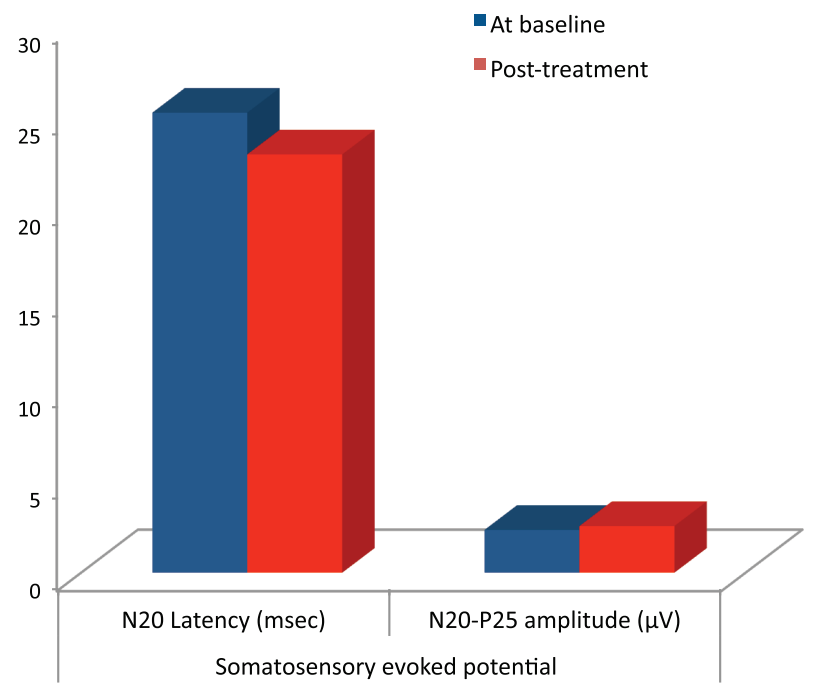

Comparison of somatosensory-evoked potential at baseline and 8 weeks after treatment among group A patients
There is extensive evidence that the evolution of poststroke deficits is paralleled by reorganization in multiple brain structures. These changes may apparently be both beneficial, such as those underlying recovery, and detrimental (may impair residual function, so-called maladaptive plasticity). Spasticity is an example of this maladaptive plasticity [10].

Table 2 Comparison of clinical and functional data at baseline and after treatment among group $B$ patients

\begin{tabular}{|c|c|c|c|c|}
\hline \multirow[t]{2}{*}{$\begin{array}{l}\text { Group B } \\
\text { patients }\end{array}$} & \multirow[t]{2}{*}{$\begin{array}{l}\text { At baseline } \\
(\text { mean } \pm S D)\end{array}$} & \multirow[t]{2}{*}{$\begin{array}{c}\text { After } \\
\text { treatment } \\
(\text { mean } \pm S D)\end{array}$} & & \\
\hline & & & $\begin{array}{c}\text { Paired } \\
t \text {-test }\end{array}$ & $P$ \\
\hline \multicolumn{5}{|l|}{ MAS } \\
\hline Wrist flexors & $2.40 \pm 0.63$ & $1.13 \pm 0.35$ & 8.264 & $0.000^{*}$ \\
\hline $\begin{array}{l}\text { Long flexors } \\
\text { of fingers }\end{array}$ & $2.47 \pm 0.52$ & $1.13 \pm 0.35$ & 10.583 & $0.000^{*}$ \\
\hline Pronators & $2.20 \pm 0.68$ & $1.20 \pm 0.25$ & 4.583 & $0.000^{*}$ \\
\hline \multicolumn{5}{|c|}{ Functional scores } \\
\hline ARAT & $22.60 \pm 3.91$ & $32.60 \pm 4.66$ & -15.811 & $0.000^{*}$ \\
\hline $\begin{array}{c}\text { Nine-hole } \\
\text { Peg Test (min) }\end{array}$ & $6.34 \pm 1.56$ & $4.38 \pm 1.10$ & 11.690 & $0.000^{*}$ \\
\hline \multicolumn{5}{|c|}{ Somatosensory-evoked potential } \\
\hline $\begin{array}{l}\text { N20 latency } \\
\text { (ms) }\end{array}$ & $26.51 \pm 3.33$ & $20.24 \pm 2.43$ & 7.703 & $0.000^{*}$ \\
\hline $\begin{array}{l}\text { N20-P25 } \\
\text { amplitude } \\
(\mu \mathrm{V})\end{array}$ & $1.80 \pm 1.24$ & $4.28 \pm 2.23$ & -3.782 & $0.002^{*}$ \\
\hline
\end{tabular}

ARAT, Action Research Arm Test; MAS, Modified Ashworth Scale. $P>0.05$, nonsignificant. ${ }^{*} P<0.05$, significant.

\section{Figure 3}

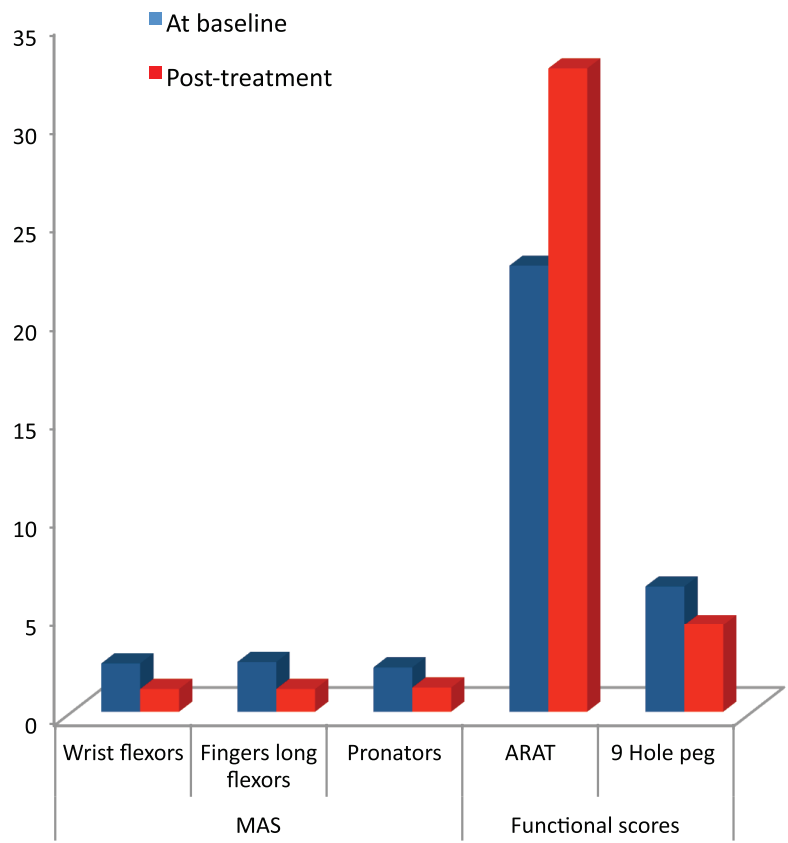

Comparison of Modified Ashworth Scale and functional data at baseline and 8 weeks after treatment among group B patients 
BTX is particularly attractive as an agent for spasticity control in the limbs in acquired brain injury. Although basic and clinical research has

\section{Figure 4}

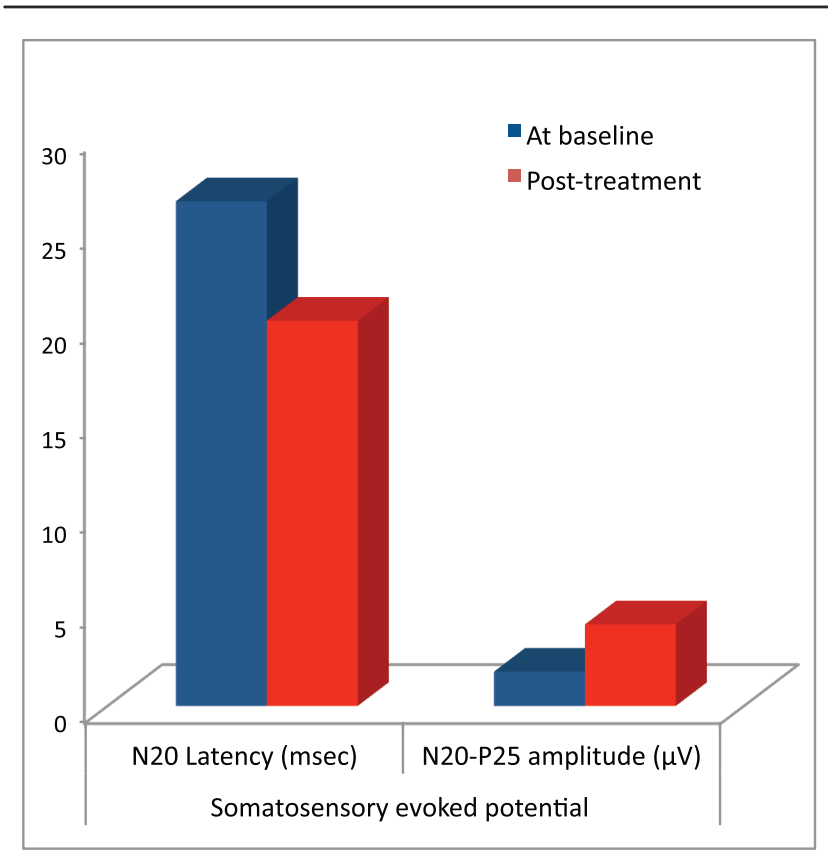

Comparison of somatosensory-evoked potential at baseline and 8 weeks after treatment among group B patients focused on the toxin's peripheral actions, BTX may act also on a central level [11].

\section{Figure 5}

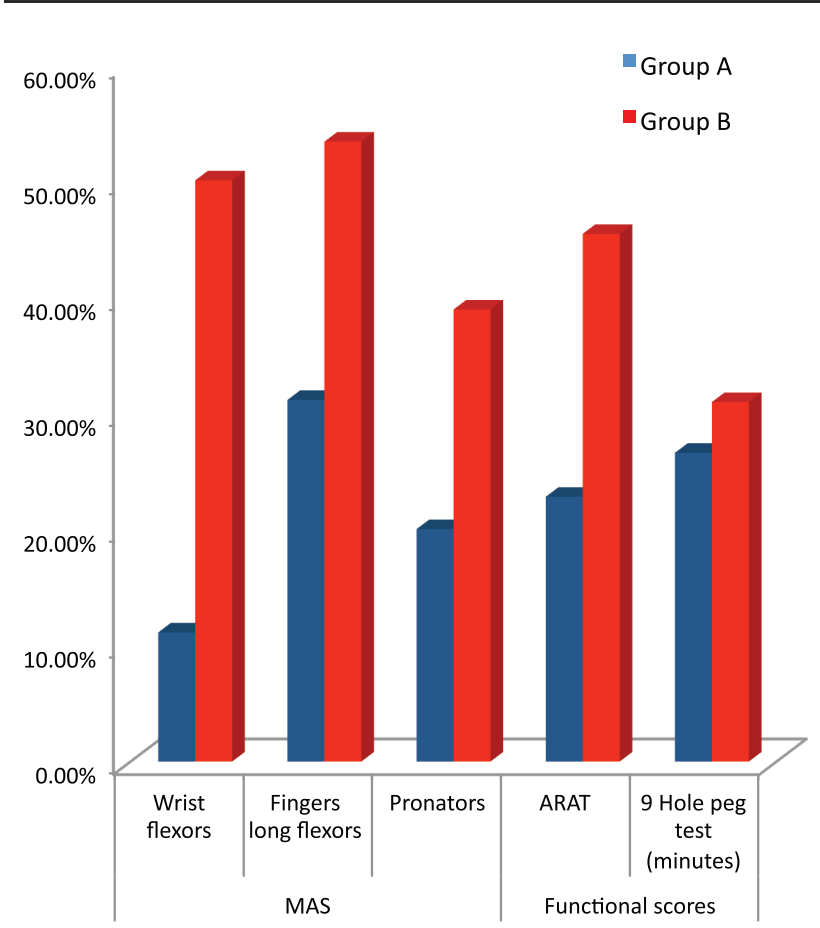

Comparison of $\Delta$ change in the Modified Ashworth Scale and functional data of group A and group B patients

Table 3 Comparison of $\Delta$ change in group A and group B patients

\begin{tabular}{|c|c|c|c|c|}
\hline \multirow[t]{2}{*}{ Data } & \multirow[t]{2}{*}{ Group A (\%) } & \multirow[t]{2}{*}{ Group B (\%) } & \multirow[b]{2}{*}{ Independent $t$-test } & \multirow[b]{2}{*}{$P$} \\
\hline & & & & \\
\hline \multicolumn{5}{|l|}{ MAS } \\
\hline \multicolumn{5}{|l|}{ Wrist flexors } \\
\hline Mean \pm SD & $11.11 \pm 66.27$ & $50.00 \pm 17.82$ & 2.195 & $0.037^{*}$ \\
\hline Range & $66.70-200.00$ & $66.70-0.00$ & & \\
\hline \multicolumn{5}{|c|}{ Long flexors of fingers } \\
\hline Mean \pm SD & $31.11 \pm 21.70$ & $53.33 \pm 11.27$ & 3.520 & $0.001^{*}$ \\
\hline Range & $66.70-0.00$ & $66.70-33.30$ & & \\
\hline \multicolumn{5}{|l|}{ Pronators } \\
\hline Mean \pm SD & $20.00 \pm 22.89$ & $38.89 \pm 29.32$ & 1.967 & 0.059 \\
\hline Range & $50-0$ & $67-0$ & & \\
\hline \multicolumn{5}{|l|}{ Functional data } \\
\hline \multicolumn{5}{|l|}{ ARAT } \\
\hline Mean \pm SD & $22.78 \pm 17.71$ & $45.40 \pm 12.78$ & -4.011 & $0.000^{*}$ \\
\hline Range & $18.20-50.00$ & $22.20-66.70$ & & \\
\hline \multicolumn{5}{|c|}{ Nine-Hole Peg Test (min) } \\
\hline Mean \pm SD & $26.56 \pm 7.01$ & $30.93 \pm 5.85$ & 1.854 & 0.074 \\
\hline Range & $42.60-17.60$ & $40.00-21.40$ & & \\
\hline \multicolumn{5}{|c|}{ Somatosensory-evoked potential } \\
\hline \multicolumn{5}{|c|}{ N20 latency (ms) } \\
\hline Mean \pm SD & $12.21 \pm 11.24$ & $13.50 \pm 5.93$ & 0.392 & 0.591 \\
\hline Range & $34.30-0.00$ & $30.30-6.20$ & & \\
\hline \multicolumn{5}{|c|}{ N20-P25 amplitude $(\mu \mathrm{V})$} \\
\hline Mean $\pm S D$ & $127.30 \pm 111.1$ & $143.59 \pm 306.55$ & 0.194 & 0.848 \\
\hline Range & $27.50-340.00$ & $20.00-950.00$ & & \\
\hline
\end{tabular}

ARAT; Action Research Arm Test; MAS; Modified Ashworth Scale. $P>0.05$, nonsignificant. ${ }^{*} P<0.05$, significant. 
Figure 6

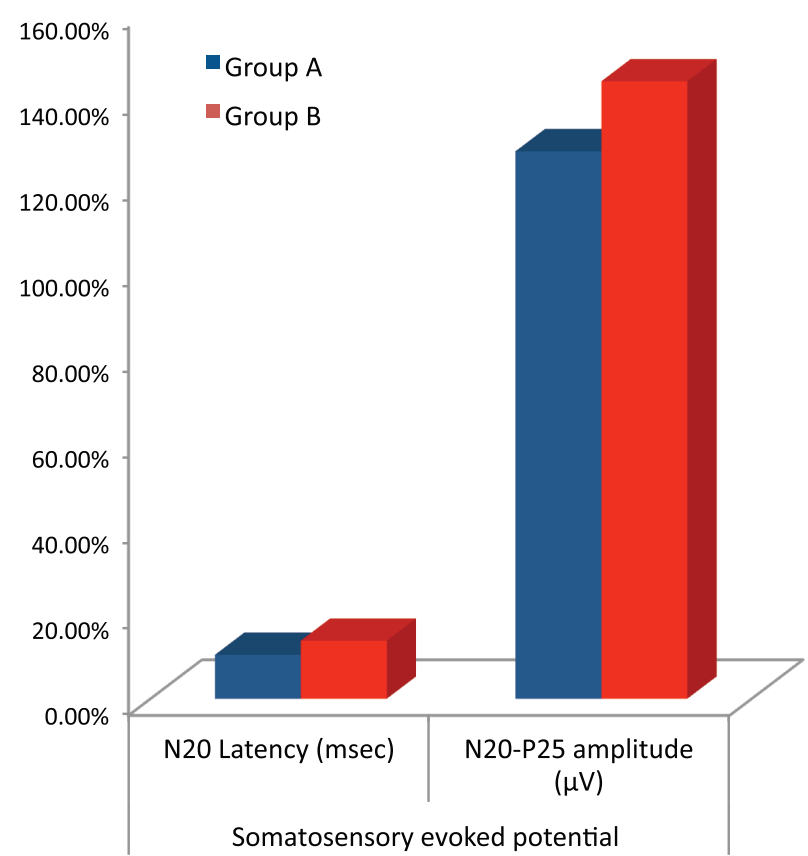

Comparison of $\Delta$ change in the somatosensory-evoked potential of group A and group B patients

SEPs studies reflect the integrity of a large cerebral zone where the key sensory and motor structures are situated [12]. SEP study before and after BTX injection could reflect the possible central action of peripherally injected BTX.

The aim of this study was to assess the clinical, functional, and cortical activation outcome of two antispastic treatments for stroke of the hand and wrist.

Our study showed improvement in the MAS after treatment in our two patient groups (with the exception of the MAS of wrist flexors in group A, which reduced after treatment but did not reach a significant value) reflecting reduction in muscle tone. The reduced tone after treatment in group $A$ is believed to be a result of the effect of different elements of our rehabilitation program. The maintained stretch increases the extensibility of the tendons. Maintained stretching can also inhibit spinal hyperexcitability through the activation of the inhibitory $\mathrm{Ib}$ afferents originated from Golgi tendon organs in response to the increase in muscle tension [13]. Moreover, applying a heating modality before stretching reduces the muscle spindles' response to stretch and renders the muscle more extensible [14].

However, in group B, it is mostly due to the effect of the peripherally injected BTX. BTX decreases the muscle tone by inhibiting acetylcholine release at the neuromuscular junction, and thus inhibits alpha motor neuron transmission and decreases muscular overactivity [15].

Our results are in agreement with the study by Shaw et al. [16], which included 333 patients with poststroke upper limb spasticity and reduced arm function. They randomized their patients to two groups: one group received BTX injection in addition to physiotherapy, and the other received physiotherapy program for 4 weeks. Their two groups showed improvement in MAS following therapy.

The percentage of change in the MAS showed greater improvement in MAS in group $\mathrm{B}$ in response to treatment when compared with group $\mathrm{A}$. This result denotes that BTX injection led to greater reduction in muscle tone when given in conjunction with rehabilitation program. This result is similar to the results obtained by Kanovský et al. [17] and Jahangir et al. [18]. In the study by Kanovský et al. [17], BTX led to a significant improvement in muscle tone 4 weeks after injection compared with placebo treatment, and, in the study by Jahangir et al. [18], BTX injection led to greater reduction in muscle tone compared with the physiotherapy and this effect of BTX on MAS in the study by Jahangir et al. [18] was sustained at 3-month follow-up.

The percentage of change in the MAS of the pronator muscle, although it showed greater reduction in group $\mathrm{B}$ when compared with group $A$, did not reach a significant level. In our study, we injected only in the pronator teres muscle, but we did not inject in the pronator quadratus; thus, the reduced tone in the pronator teres may not be evident when assessing the tone of the pronator muscle group as a whole, and this may explain the nonsignificant reduction in pronator muscles.

As regards upper limb function, there was a significant improvement in upper limb function after treatment in group B. This improvement in hand function could be the result of the cortical reorganization and normalization of the cortical activity associated with peripherally injected BTX [19]. However, the improvement in function may not only be a direct effect of BTX but also be an indirect effect of the combined BTX injection and rehabilitation program that led to reduction in tone and increase in range of motion in joints [20].

Our results are in agreement with Veverka et al. [19], Veverka et al. [21], and Tomáŝová et al. [22]. 
The authors reported improvement in the upper extremity strength, and functional scores 4 weeks after BTX injection.

Group A also showed improvement in upper limb function after treatment when compared with that of the baseline. Our results are supported by a metaanalysis randomized study by Ada et al. [23], which has demonstrated that strengthening exercise in the form of biofeedback, electrical stimulation, muscle reeducation, progressive resistance exercise, and mental practice increases strength, improves activity, and does not increase spasticity. Similar to our results, Alon et al. [24] found improved hand function measured using the Nine-Hole Peg Test, Box and Blocks Test, and JebsenTaylor Test after a home-based rehabilitation program including stimulation program combining activation of the wrist-fingers flexors and extensors with functional grasp, hold, and release training for 5 weeks. Moreover, Haji-Ahmad et al. [25] observed reduction in wrist and finger spasticity and improvement in range of motion and activities of daily living measured using the Barthel index following myofeedback sessions combined with occupational therapy compared with occupational therapy only.

Comparison of the percentage of change in functional data between the two patient groups in response to treatment showed better improvement in the ARAT in group B than in group A, implicating a positive effect of BTX injection on hand motor function. This result is different from the results obtained by Wolf et al. [26]. In the study, their 25 patients with poststroke spasticity were randomly selected to receive either BTX-A or saline, followed by $12-16$ exercise sessions. They found improvement in hand function in the two groups after treatment. However, they did not find a significant difference between the two groups in functional outcome. The difference between our study and the study by Wolf et al. [26] may be attributed to the difference in BTX regimen used. In the study by Wolf et al. [26], a fixed dose of BTX injection was used, whereas in our study the dose of botulinum toxin was administered according to each patient's individual pattern and severity of spasticity. Moreover, in this study, we used the ARAT to assess the hand function, whereas Wolf et al. [26] used the Wolf Motor Function Test.

Although the percentage of change in the Nine-Hole Peg Test was lower in group B when compared with group $\mathrm{A}$, it did not reach a significant value. This finding may indicate that the Nine-Hole Peg Test is less sensitive compared with the ARAT in detecting changes in the upper dexterous function. Similarly, Lin et al. [27] found that the ARAT and Box and Blocks Test are more appropriate compared with the NineHole Peg Test in relation to responsiveness and validity.

In our study we performed the SEP to assess the cortical activity. As the spontaneous recovery from stroke occurs during the first 3 months following injury, all our patients were recruited with a disease duration of at least 3 months; thus, any change in cortical activity will be the result of the treatment rather than being a part of the natural recovery mechanism.

Previous work on the effect of spasticity on SEPs suggested that the neurophysiological characteristics of spasticity may contribute to the SEP abnormalities $[3,28]$. SEPs are mediated by Ia large diameter sensory fibers in peripheral nerves and the dorsal columnmedial lemniscal system in the central nervous system. The alteration of SEPs in cases of spasticity can be attributed to a well-known phenomenon that occurs in normal individuals in whom there is a depression of SEPs during muscle activation and complete absence during strong muscle cocontraction. This depression is induced by various centrifugal and centripetal gating mechanisms, where centrifugal gating refers to inhibition of sensory signal by interaction with efferent motor signals. However, centripetal gating refers to the modulation that occurs through the interaction between different afferent signals [2].

Another hypothesis states that SEP depression is the result of impingement of segmental and suprasegmental sensory relay originating from abnormally functioning primary afferent pathway of spastic muscles [3].

At 8 weeks after treatment, group B showed improvement in the N20 latency and N20-P25 (reduction in N20 latency and increase in N20-P25 amplitude) when compared with baseline. This finding is in accordance with Basaran et al. [2] and Frascarelli et al. [3]. The authors attributed this finding to the fact that peripherally injected BTX affects both extrafusal and intrafusal muscle fibers and reduced group I muscle spindle and possible group II afferent input to the spinal cord. This would lead to a reduction in the tonic presynaptic gating. This change in sensory input to the somatosensory system following BTX injection may lead to central reorganization in the parietal cortex. Basaran et al. [2] also mentioned that the 
muscle spindle is the starting point in proprioception function to the central nervous system, which under the spasticity burden fails to function properly, with resultant proprioception deterioration and functional disabilities. BTX injection-induced modulation of sensory signal input to somatosensory cortex can improve proprioception and hence improve function.

This finding is also supported by the studies by Veverka et al. [21] and Tomáŝová et al. [22], in which functional magnetic resonance examination was conducted to study the effect of peripherally injected BTX of the cortical activity. In these studies the peripherally injected BTX induced clear reduction in the extent and also more prominent lateralization of the extensive, mostly bilateral, network of active areas in primary and nonprimary sensorimotor regions during the performance of a motor at the baseline examination.

BTX -induced effect on cortical activity was postulated to be the result of its peripheral action. BTX alters sensory input to the central nervous system and reduces I afferent signals and hence indirectly induces secondary changes at different levels of the motor system and cerebral cortex [21].

In group A there was a significant reduction in N20 latency after treatment; although the N20-P25 improved after treatment, it did not reach a significant value. This may denote that N20 latency is more sensitive compared with N20-P25 amplitude to changes in cortical activity after treatment. We assume that our rehabilitation program induced reduction in the $\alpha$-motor neuron excitability, as muscle stretching and contract-relax proprioceptive neuromuscular facilitation (PNF) stretching have the capacity to reduce the motor neuron $[29,30]$. Moreover, thermotherapy can reduce the activity of gamma afferent fibers and inhibits $\alpha$-motor neuron impulses [31]. This modulation of the sensory input to the spinal cord could affect the somatosensory cortex in the same way BTX injection did.

\section{Conclusion}

We conclude that BTX injection in conjunction with rehabilitation program is more efficient compared with conventional rehabilitation alone in the management of upper limb spasticity.

Both BTX injection and conventional rehabilitation program improved the cortical activity in patients with poststroke upper limb spasticity.

\section{Recommendations}

We recommend utilization of BTX in conjunction with rehabilitation program in the treatment of upper limb spasticity. We also recommend further studies on the effect of BTX on cortical activity.

\section{Financial support and sponsorship \\ Nil.}

\section{Conflicts of interest}

There are no conflicts of interest.

\section{References}

1 Bergfeldt $U$, Jonsson T, Bergfeldt L, Julin P. Cortical activation changes and improved motor function in stroke patients after focal spasticity therapy-an interventional study applying repeated fMRI. BMC Neurol 2015; 15:52-63.

2 Basaran A, Emre U, Karadavut KI, Bulmus N. Somatosensory evoked potentials of hand muscles in stroke and their modification by botulinum toxin: a preliminary study. J Rehabil Med 2012; 44:541-546.

3 Frascarelli F, Di Rosa G, Bisozzi E, Castelli E, Santilli V. Neurophysiological changes induced by the botulinum toxin type $A$ injection in children with cerebral palsy. Eur J Paediatr Neurol 2011; 15:59-64.

4 Bohannon RW, Smith MB. Interrater reliability of a modified Ashworth scale of muscle spasticity. Phys Ther 1987; 67:206-207.

5 Lyle RC. A performance test for assessment of upper limb function in physical rehabilitation treatment and research. Int J Rehabil Res 1981; 4:483-492.

6 Sharpless JW. The Nine Hole peg test of finger hand coordination for the hemiplegic patient. In: Sharpless JW, editor. Mossman's a problem orientated approach to stroke rehabilitation, 2nd ed. Illinois: Charles C Thomas; 1982. pp. 420-423.

7 American Electro-encephalography Society. Recommended standards for short-latency somatosensory evoked potentials. J Clin Neurophysiol 1984; 1:6-14.

8 Armagan O, Tascioglu F, Oner C. Electromyographic biofeedback in the treatment of the hemiplegic hand: a placebo-controlled study. Am J Phys Med Rehabil 2003; 82:856-861.

9 Urban PP, Wolf T, Uebele M. Occurrence and clinical predictors of spasticity after ischemic stroke. Stroke 2010; 41:2016-2020.

10 Pascual-Leone A, Amedi A, Fregni FL. The plastic human brain cortex. Annu Rev Neurosci 2005; 28:377-401.

11 Curra' A, Trompetto C, Abbruzzese G, Berardelli A. Central effects of botulinum toxin type A. Evidence and supposition. Mov Disord 2004; S8:60-64.

12 Tzvetanov P, Rousseff RT, Atanassova P. Prognostic value of median and tibial somatosensory evoked potentials in acute stroke. Neurosci Lett 2005; 380:99-104.

13 Suzuki T, Fujiwara T, Tani M, Saitoh E. Characteristics of the F-wave and $\mathrm{H}$-reflex in patients with cerebrovascular diseases: a new method to evaluate neurological findings and effects of continuous stretching of the affected arm. In: Turker $\mathrm{H}$, editor. Electrodiagnosis in new frontiers of clinical research. 1st ed. Rijeka: InTech; 2013. pp. 25-42.

14 Lee GP, Ng GY. Effects of stretching and heat treatment on hamstring extensibility in children with severe mental retardation and hypertonia. Clin Rehabil 2008; 22:771-779.

15 Nigam PK, Nigam A. Botulinum toxin. Indian J Dermatol 2010; 55:8-14.

16 Shaw LC, Price Cl, van Wijck FM, Shackley P, Steen N, Barnes MP, et al. Botulinum toxin for the upper limb after stroke (BoTULS) trial: effect on impairment, activity limitation, and pain. Stroke 2011; 42:1371-1379.

17 Kanovský P, Slawek J, Denes Z, Platz T, Sassin I, Comes G, et al. Efficacy and safety of botulinum neurotoxin NT 201 in poststroke upper limb spasticity. Clin Neuropharmacol 2009; 32:259-265.

18 Jahangir AW, Tan HJ, Norlinah MI, Nafisah WY, Ramesh S, Hamidon BB, et al. Intramuscular injection of botulinum toxin for the treatment of wrist and finger spasticity after stroke. Med J Malaysia 2007; 62:319-322.

19 Veverka T, Hluštík $\mathrm{P}$, Tomášová Z, Hok $\mathrm{P}$, Otruba $\mathrm{P}, \mathrm{Král} \mathrm{M}$, et al. BoNT-A related changes of cortical activity in patients suffering from severe hand 
paralysis with arm spasticity following ischemic stroke. J Neurol Sci 2012; 319:89-95.

20 Yazdchi M, Ghasemi Z, Moshayedi H, Rikhtegar R, Mostafayi S, Mikailee H, et al. Comparing the efficacy of botulinum toxin with tizanidine in upper limb post stroke spasticity. Iran J Neurol 2013; 12:47-50.

21 Veverka T, Hluštík P, Hok $\mathrm{P}$, Otruba $\mathrm{P}$, Tüdös Z, Zapletalová J, et al. Cortical activity modulation by botulinum toxin type $A$ in patients with poststroke arm spasticity: real and imagined hand movement. J Neurol Sci 2014; 346:276-283

22 Tomáŝová Z, Hluŝtík $\mathrm{P}$, Král $\mathrm{M}$, Otruba $\mathrm{P}$, Herzig $\mathrm{R}$, Krobot $\mathrm{A}$, et al. Cortical activation changes in patients suffering from post-stroke arm spasticity and treated with botulinum toxin A. J Neuroimaging 2013; 23:337-344

23 Ada L, Dorsch S, Canning CG. Strengthening interventions increase strength and improve activity after stroke: a systematic review. Aust J Physiother 2006; 52:241-248.

24 Alon G, Sunnerhagen KS, Geurts AC, Ohry A. A home-based, selfadministered stimulation program to improve selected hand functions of chronic stroke. Neurorehabilitation 2003; 18:215-225.

25 Haji-Ahmad T, Haghgoo HA, Pishyareh E, Zahedan AB. The effect of biofeedback therapy on hand function and daily activities in stroke survivors. Zah J Res Med Sci 2015; 17:29-33.
26 Wolf SL, Milton SB, Reiss A, Easley KA, Shenvi NV, Clark PC. Further assessment to determine the additive effect of botulinum toxin type $A$ on an upper extremity exercise program to enhance function among individuals with chronic stroke but extensor capability. Arch Phys Med Rehabil 2012; 93:578-587.

27 Lin KC, Chuang LL, Wu CY, Hsieh YW, Chang WY. Responsiveness and validity of three dexterous function measures in stroke rehabilitation. $J$ Rehabil Res Dev 2010; 47:563-571.

28 Park ES, Park Cl, Kim DY, Kim YR. The effect of spasticity on cortical somatosensory-evoked potentials: changes of cortical somatosensoryevoked potentials after botulinum toxin type A injection. Arch Phys Med Rehabil 2002; 83:1592-1596.

29 Suzuki T, Saitoh E, Tani M, Nabeta R, Daikuya S, Hirose H, et al. Effect of continued stretching of the affected arm in patients with cerebrovascular diseases by examining $\mathrm{H}$-reflex characteristics. Electromyogr $\mathrm{Clin}$ Neurophysiol 2003; 43:51-56.

30 Etnyre BR, Abraham LD. H-reflex changes during static stretching and two variations of proprioceptive neuromuscular facilitation techniques. Electroencephalogr Clin Neurophysiol 1986; 63:174-179.

31 Matsumoto S, Kawahira K, Etoh S, Ikeda S, Tanaka N. Short-term effects of thermotherapy for spasticity on tibial nerve F-waves in post-stroke patients. Int J Biometeorol 2006; 50:243-250. 